CHALMERS

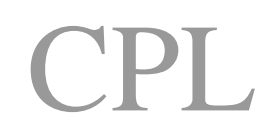

Chalmers Publication Library

Institutional Repository of

Chalmers University of Technology

http://publications.lib. chalmers.se

Copyright notice (post print) Taylor \& Francis

This is an electronic version of an article published in Computer Methods in Biomechanics and Biomedical Engineering.

http://dx.doi.org/10.1080/10255842.2010.535523 


\title{
Active Muscle Response using Feedback Control of a Finite Element Human Arm Model
}

\author{
J. Östh*a ${ }^{\mathrm{a}}$ K. Brolin ${ }^{\mathrm{a}}$, and R. Happee \\ ${ }^{a}$ Department of Applied Mechanics, Chalmers University of Technology, Gothenburg, Sweden \\ ${ }^{b}$ Faculty of Mechanical, Maritime and Materials Engineering, Delft University of Technology, \\ Delft, the Netherlands \\ *Corresponding author. Email: jonas.osth@chalmers.se
}

\begin{abstract}
Mathematical Human Body Models (HBM) are important research tools that are used to study the human response in car crash situations. Development of automotive safety systems requires the implementation of active muscle response in HBM, as novel safety systems also interact with vehicle occupants in the precrash phase. In this study, active muscle response was implemented using feedback control of a non-linear muscle model in the right upper extremity of a Finite Element (FE) HBM. Hill-type line muscle elements were added and the active and passive properties were assessed. Volunteer tests with low impact loading resulting in elbow flexion motions were performed. Simulations of posture maintenance in a gravity field and the volunteer tests were successfully conducted. It was concluded that feedback control of a non-linear musculoskeletal model can be used to obtain posture maintenance and human-like reflexive responses in an FE HBM.
\end{abstract}

Keywords: finite element; human body model; active muscle; feedback control; posture maintenance; upper extremity 


\section{Introduction}

Road traffic accidents are among the top leading causes of death worldwide. In the European Union, there are about 43,000 reported deaths (ETSC 2008) and 1.3 million casualties because of road traffic accidents each year (European Commission 2001). To prevent accidental injuries, it is vital to understand the mechanics of injury in biological tissues. For traffic safety research addressing this problem Human Body Models (HBM) are important tools. The HBM can be Multi Body (MB) or Finite Element (FE) models. The MB models consist of rigid bodies connected with joints defined by kinematical constraints and can predict occupant kinematics at a relatively low computational cost with relatively simple models. FE models can be more detailed and have the advantage of providing stress and strain data for individual tissues. Therefore, they are well suited to study injury mechanics, to find injury tolerances, determine risk functions, and in the design of preventive systems.

Recent development of automotive safety systems imposes new requirements on HBM. Systems that can detect and prevent accidents are integrated with systems that become active when the accident is occurring (Aparicio 2005). The occupant's interaction with safety systems in the pre-crash phase will change the injury outcome in the crash phase. Therefore, HBM that are biofidelic in the pre-crash phase and during the crash phase can be used to study how the integrated safety systems change the injury risk during crash scenarios. FE HBM models used today lack two features that are important for simulation of pre-crash scenarios:

- Posture maintenance is not simulated with current FE HBM, thus they collapse during long pre-crash simulations and will not maintain a realistic occupant posture.

- Reflexive muscle responses have not been implemented, thus FE HBM and will not react in a realistic manner to pre-crash vehicle accelerations, belt pretension, etcetera.

To model these functions with an FE HBM requires the implementation of active musculature and a model of the Central Nervous System (CNS) control.

Active musculature has previously been implemented in several HBMs for impact simulations. The influence of reflexive muscular response has been modeled by ramping muscle activation to a maximum level (de Jager 1996; Wittek 2000; van der Horst 2002; Brolin et al. 2005). This simplified approach shows the importance of muscle activation for the occupant response. Chancey et al. (2003) used an optimization strategy to estimate muscle activation levels for individual neck muscles in MB simulations of a relaxed, posture maintaining state and a maximally tensed state. Brolin et al. (2008) made simulations with an FE neck and evaluated the protective effect of muscle tension in the cervical spine for helicopter crash scenarios. Similarly, Hedenstierna and Halldin (2008) simulated volunteer experiments with muscle activation. These three studies used optimization strategies to reach an almost static condition that maintains posture for short durations. Behr et al. (2006) studied the effect of muscular tension in the lower extremities by applying experimentally determined muscle activation levels for an emergency braking maneuver with an FE HBM. While this is a valid approach, its use is limited to the analysis of available volunteer data. All of the studies above have the disadvantage that the muscular response of the human model is pre-defined as a function of time. 
Another approach to simulating muscle activation is feedback control. This may capture the actual human postural and reflexive control. Feedback control has been used to model the standing human, Barin (1989) and Kou (2005), and to model the postural control of the upper extremity, Gerdes and Happee (1994) and Brouwn (2000). Feedback, intrinsic stiffness, and damping parameters for the neuromuscular control of the upper extremities have been estimated using continuous force perturbations (de Vlugt et al. 2006). Feedback control can also simulate occupant bracing, since it can balance the co-contraction so that no net moment is generated around a joint. Recent efforts have been made with MB HBM by which simulations of posture maintenance were attempted using feedback control. Cappon et al. (2007) stabilized the spine using feedback proportional, integral, and derivative (PID) controlled torque actuators between each vertebra; they studied the effect on occupant response in a rollover situation. They concluded that the next step would be to model the active human response with line muscle elements instead of torque actuators. Budsziewski et al. (2008) made an attempt to use feedback PID control of an upper extremity model. Fraga et al. (2009) used feedback PID control of line muscle elements to stabilize the head of a motorcycle rider in lateral and longitudinal maneuvers for MB simulations. To the best of our knowledge, there are no published results of feedback PID control of line muscle elements in simulations with deformable FE HBM.

Differences between FE and $\mathrm{MB}$ HBM that are anticipated to influence the implementation of feedback control are the deformation of bones and tissues in between joints and the difference in joint definitions. Bone and joint surface deformation will introduce additional dynamics which may induce numerical challenges due to localized deformation, and they will affect system dynamics, possibly leading to closed loop instability.

An FE HBM with feedback PID-control of line muscle elements would be able to maintain its posture in pre-crash simulations of several seconds. Also, reflexive responses could be modeled. An FE HBM can better simulate occupant interactions with vehicle interior and restraints than MB HBM due to differences in contact algorithms. An FE HBM would also be able to predict injuries occurring in the pre-crash and crash phase, thereby reducing the number of models needed to perform a combined analysis.

Therefore, the aim of this paper is to address the challenges of implementing feedback control of a muscle material model in an FE HBM, compared to previous MB HBM implementations. To study this, the upper extremity was chosen as a subsystem of the full human body, and feedback control was implemented for the elbow joint. 


\section{Method}

The right arm and shoulder complex of the FE HBM Total HUman Model for Safety version 3.0 was used in this study (Toyota Motor Corporation 2008), hereafter called the THUMS ${ }^{\circledR}$. Upper extremity muscles spanning the elbow joint were added according to Section 2.1. Feedback control was implemented with a PID controller in the object version of the FE code LS-DYNA $^{\circledR}$ version 970 (Hallquist 2006), as described in Section 2.2. Volunteer experiments in which force pulses were applied to produce elbow flexion motions were performed according to Section 0. Simulations were made with the model as described in Section 0. The active and passive properties were assessed by comparison with published data, posture maintenance in a gravity field was verified, and the volunteer tests were simulated.

All pre and post processing in this study was done using LS-PREPOST ${ }^{\circledR}$ (LSTC Inc., Livermore, CA, USA) and MatLab ${ }^{\circledR}$ (The Mathworks Inc., Natick, MA, USA).

\subsection{Musculoskeletal model}

The THUMS ${ }^{\circledR}$ that provided the skeletal geometry of the model is an FE model of a $50^{\text {th }}$ percentile adult male vehicle occupant. It contains approximately 150,000 elements of which 7,400 belong to the right arm and shoulder complex. Cancellous bone and soft tissues are modeled with solid elements, cortical bone with shell elements, and ligaments with both shell and beam elements. The cancellous bone, soft tissues, and ligaments are modeled with elastic materials, while the cortical bone is modeled with a piecewise linear plasticity model. More detail on the THUMS ${ }^{\circledR}$ has been published by the Toyota Motor Corporation (2008). Only the right arm and shoulder complex of the full body model was used. The remaining elements were deleted together with all associated information.

Two versions of the elbow joint model were used for simulations, one with the original elbow joint intact and another one where this was replaced by a revolute joint. The original elbow joint is modeled with a frictionless sliding contact between the humerus and ulna (Toyota Motor Corporation 2008). The motion is constrained by the ulnar collateral ligament, the radial collateral ligament, and the anular ligament, as well as by contacts between the soft tissues of the upper and lower arm. In the model with the revolute joint, the radial and ulnar collateral ligaments and the contacts that define the elbow joint were removed. The alar ligament that connects the radius to the ulna was kept in both versions. The added revolute rigid body joint has a stiffness of $0.6 \mathrm{Nm} \mathrm{rad}^{-1}$ between the $25^{\circ}$ and $130^{\circ}$ flexion angles. For values outside this range the stiffness of the rigid body joint increases significantly to $60 \mathrm{Nm} \mathrm{rad}^{-1}$, based on the mean of the stiffness interval $38-86 \mathrm{Nm} \mathrm{rad}^{-1}$ for hyperextension reported by Engin and Chen (1987).

The THUMS ${ }^{\circledR}$ does not include any muscles for the upper extremities. Therefore, muscles were added based on data from anatomical textbooks (Standring 2005; Marieb 1998), see Figure 1. The muscles spanning the elbow joint have large attachment areas and attach to several bones. Hence, brachialis was divided into two muscle elements, with a common ulnar attachment but with separate humeral attachments. Biceps brachii were divided in to the long and short heads. Triceps were divided into five parts: the first two represent the line of action of the long and lateral heads of triceps, while the rest represent the spread-out humeral attachment of the medial head. The triceps connections to the olecranon process of the ulna were retracted $20 \mathrm{~mm}$ by the addition of three rigid beams to increase the length of the triceps 
lever arm. The lower arm muscles, brachioradialis, pronator teres, and extensor carpi radialis longus, all of which contribute to elbow flexion (Wilkie 1950; Murray et al. 2000), are also included in the model. A summary of the muscles included, division into number of elements, muscle action, and muscle specific parameters can be found in Table 1 .

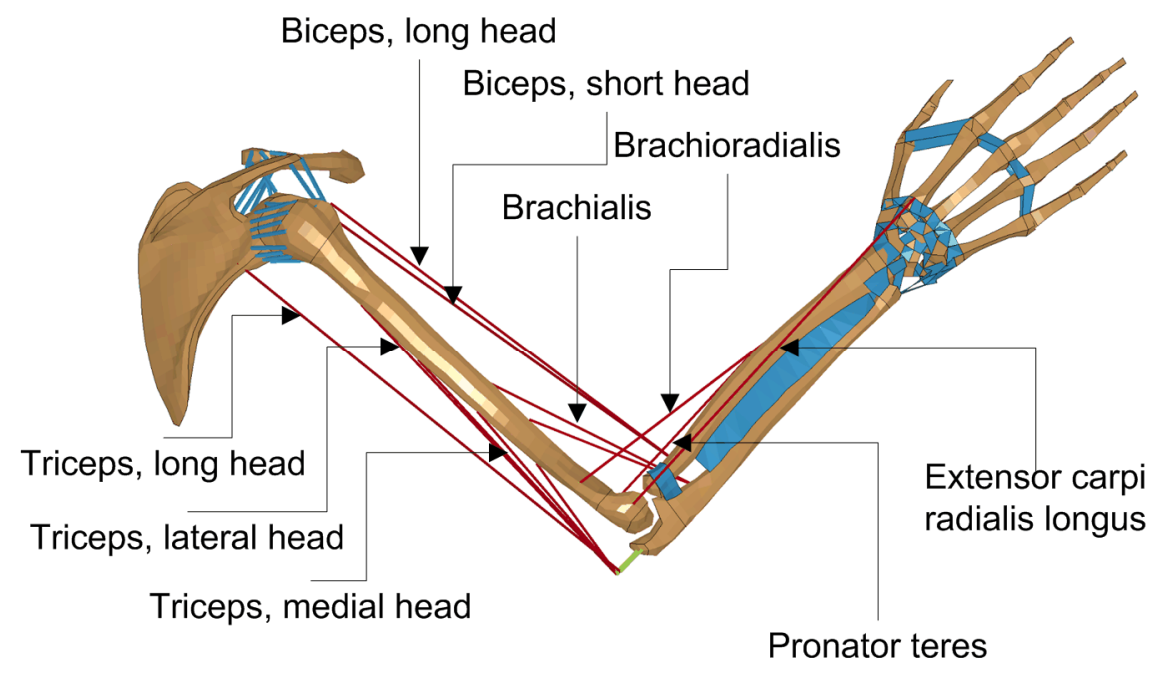

Figure 1. Muscles added to the FE model (THUMS ${ }^{\circledR}$, Toyota Motor Corporation 2008).

The muscles were implemented using line elements with a Hill-type (Hill 1970) material model. Muscle material parameters that are shared by all muscles are listed in Table 2. The characteristics of the contractile part of the muscle material model are given by normalized muscle length and shortening velocity shape functions. The contractile stress, $\sigma_{c}$, of a line muscle element is defined as

$$
\sigma_{c}=N_{a}(t) f_{l}(l) f_{v}(v) \sigma_{\max }
$$

where $\sigma_{\max }$ is the maximum isometric contractile stress of the muscle. The shape functions, $f_{l}$ and $f_{v}$, scale the contractile stress with respect to current muscle length and shortening velocity, and $N_{a}(t)$ is the muscle activation level.

The maximum contractile stress, $\sigma_{\max }$, together with the Physiological Cross Sectional Area (PCSA), determines the maximum force, $F_{m}$, a muscle can generate. The maximum contractile stress of the current model is based on the suggestion by Winters and Stark (1988). The PCSA of the muscles included in the current model are based on the data summarized by Holzbaur et al. (2005). The cadaveric PCSA values were increased by $60 \%$ for all muscles in the current model, similar to Chancey et al. (2003).

The force-length relation of the contractile muscle stress is approximated by (Wittek and Kajzer 1997):

$$
f_{L}(l)=\exp \left\{-\left[\left(l / l_{\text {opt }}-1\right) / C_{s h}\right]^{2}\right\}
$$

The shape factor $C_{s h}$ for the flexor muscles is estimated from the excursion capacities published by Murray et al. (2000). Here, $C_{s h}$ for the extensor muscles is estimated to fit the shape of the maximum isometric extension moment found by Buchannan et al. (1998). The 
optimum length, $l_{o p t}$, of both flexor and extensor muscle elements is determined so that the maximum isometric moment coincides with the experiments of Buchannan et al. (1998).

The force-velocity relation, $f_{v}$, is a version of Hill's equation (Hill 1970), refined by Winters and Stark (1985) to include eccentric shortening. The form in the equation is given by Wittek and Kajzer (1997):

$$
f_{v}(V)=\left\{\begin{array}{cc}
0 & v \leq-1 \\
(1+v) /\left(1-v / C_{\text {short }}\right) & -1<v \leq 0, \quad v=V / V_{\text {max }} \\
{\left[1+v\left(C_{\text {mvl }} / C_{\text {leng }}\right)\right] /\left(1+v / C_{\text {leng }}\right)} & v>0
\end{array}\right.
$$

where the shape of $f_{v}$ is determined by three constants, $C_{i}$, and the maximum shortening velocity of the muscle, $V_{\max }$. Here, $C_{\text {short }}$ determines the shape for concentric shortening, while $C_{\text {leng }}$ determines the transition between concentric shortening and eccentric lengthening of the muscle; $C_{m v l}$ determines the asymptotic value for increasing eccentric lengthening speeds. The values of the constants, $C_{i}$, are chosen to fit the model force-velocity characteristics to the experimental data given by Hortobágyi and Katch (1990) for a $V_{\max }=5 l_{\text {opt }}$.

The parallel elastic part of the muscle material model is approximated by (Wittek and Kajzer 1997):

$$
\sigma_{p e}(l)=\left\{\sigma_{\max } /\left[\exp \left(C_{p e}\right)-1\right]\right\}\left\{\exp \left[\left(C_{p e} / P E_{\max }\right)\left(l / l_{o p t}-1\right)\right]-1\right\}
$$

where the parameter, $P E_{\max }$, represents the amount of strain when the stress of the passive element is equal to $\sigma_{\max }$. With the values of $P E_{\max }$ and $\sigma_{\max }$ in Table 2, the value of $C_{p e}$ for the flexor muscles is based on a curve fit of the passive elastic stiffness of the biceps brachii muscle presented by Yamada (1970). The value of $C_{p e}$ for the extensor (triceps) muscle is chosen to give an even slope of the passive stiffness in the transition from flexion to extension motions. Also included in the parallel part of the muscle element is damping proportional to the shortening velocity so that:

$$
\sigma_{d}(V)=\left(D / l_{o p t}\right) V
$$

where the damping constant, $D$, for the muscle elements were equal for all muscle elements and set to achieve reasonable damping of the elbow joint in comparison with experimental studies (Hayes and Hatze 1977). 
Table 1. The muscles implemented and their properties.

\begin{tabular}{|c|c|c|c|c|c|c|c|c|c|}
\hline Muscle & Action & Division & Origin & Insertion & $\begin{array}{l}\mathrm{PCSA}^{1} \\
{\left[\mathrm{~mm}^{2}\right]}\end{array}$ & $\begin{array}{l}\text { Element } \\
\text { length } \\
{[\mathrm{mm}]}\end{array}$ & $\begin{array}{l}l_{\mathrm{opt}} \\
{[\mathrm{mm}]}\end{array}$ & $\begin{array}{l}\mathrm{C}_{\mathrm{sh}} \\
{[-]}\end{array}$ & $\begin{array}{l}\text { Actual } \\
\text { fiber } \\
\text { length }^{2} \\
{[\mathrm{~mm}]}\end{array}$ \\
\hline \multirow[t]{2}{*}{ Biceps brachii } & Flexor & Long head & $\begin{array}{l}\text { Glenohumeral joint } \\
\text { (Scapula) }\end{array}$ & Radial tuberosity & 720 & 286 & 277 & 0.14 & 136 \\
\hline & & Short head & $\begin{array}{l}\text { Coracoid process } \\
\text { (Scapula) }\end{array}$ & Radial tuberosity & 496 & 320 & 310 & 0.21 & 150 \\
\hline \multirow[t]{2}{*}{ Brachialis } & Flexor & Element 1 & Humerus & Ulnar tuberosity & 568 & 159 & 150 & 0.50 & 90 \\
\hline & & Element 2 & Humerus & Ulnar tuberosity & 568 & 119 & 111 & 0.60 & 90 \\
\hline Brachioradialis & Flexor & & Humerus & Radius, distal end & 304 & 251 & 251 & 0.14 & 164 \\
\hline Pronator teres & Flexor & & $\begin{array}{l}\text { Medial epicondyle } \\
\text { of humerus }\end{array}$ & Radius, medial & 640 & 137 & 132 & 0.35 & 56 \\
\hline $\begin{array}{l}\text { Exetensor carpi } \\
\text { radialis longus }\end{array}$ & Flexor & & $\begin{array}{l}\text { Supracondylar } \\
\text { ridge of humerus }\end{array}$ & Second metacarpal & 352 & 292 & 289 & 0.35 & 78 \\
\hline \multirow[t]{5}{*}{ Triceps } & Extensor & Long head & Scapula & Olecranon process & 912 & 331 & 338 & 0.64 & 102 \\
\hline & & Lateral head & Humerus & Olecranon process & 720 & 247 & 255 & 0.48 & 84 \\
\hline & & Medial head, element 1 & Humerus & Olecranon process & 240 & 194 & 204 & 0.64 & 63 \\
\hline & & Medial head, element 2 & Humerus & Olecranon process & 240 & 141 & 157 & 0.87 & 63 \\
\hline & & Medial head, element 3 & Humerus & Olecranon process & 240 & 90 & 100 & 1.34 & 63 \\
\hline
\end{tabular}

${ }^{1}$ PCSA used are $160 \%$ of the values reported by Holzbaur et al. (2005).

${ }^{2}$ Actual fiber lengths from An et al. (1981). 


\subsection{Controller model}

The postural and reflexive feedback control of the CNS is modeled with a PID controller. Figure 2 shows a schematic representation of the closed loop system implemented. The box on the right shows the musculoskeletal model as described in Section 2.1. The box on the left contains the controller and activation dynamics model, which are implemented with a user control subroutine.

For the closed loop system in Figure 2, the feedback signal, $y(t)$,is the elbow joint flexion angle, which represents different possible proprioceptive feedback signals. The controller has an input reference signal, $r(t)$, representing the desired elbow angle that is constant for the intended application of the model. The neural delays, due to the time needed for the nerve signals to be conveyed back and forth to the CNS, are lumped into one single delay for the afferent signal as it enters the controller. In the model the neural delay, $T_{d e}$, is based on the estimation for elbow muscle reflexes made by de Vlugt et al. (2006). The delayed signal, $y_{d}(t)$, is then compared with the reference signal, $r(t)$, and a control signal, $u(t)$, is generated:

$$
\begin{gathered}
e(t)=r(t)-y_{d}(t) \\
u(t)=k_{p} * e(t)+k_{i} * \int_{0}^{t} e(\tau) d \tau+k_{d} * d e(t) / d t
\end{gathered}
$$

In Equation 2.7, $k_{p}, k_{i}$, and $k_{d}$ are the proportional, integral, and derivative gains of the PID controller. The derivative part of Equation 2.7 is low-pass filtered by a first order filter with a time constant, $T_{f}$, that appears as a fourth parameter which determines the performance of the controller.

The control signal, $u(t)$, describes the desired elbow flexion moment. The actual input to the muscles is derived through scaling by the summed maximum isometric flexion moment, $M_{f}$, and extension moment, $M_{e}$. If $u(t)$ is positive, all flexor muscles are activated with $m_{f}=u(t) / M_{f}$, while all extensors receive an $m_{e}=-u(t) / M_{e}$ input leading to deactivation. For a negative $u(t)$ the opposite will happen, extensors are activated with $m_{e}=|u(t)| / M_{e}$ and flexors receive an $m_{f}=-|u(t)| / M_{f}$ input leading to deactivation. An initial co-contraction level as a percentage of full extensor muscular activation can be defined.

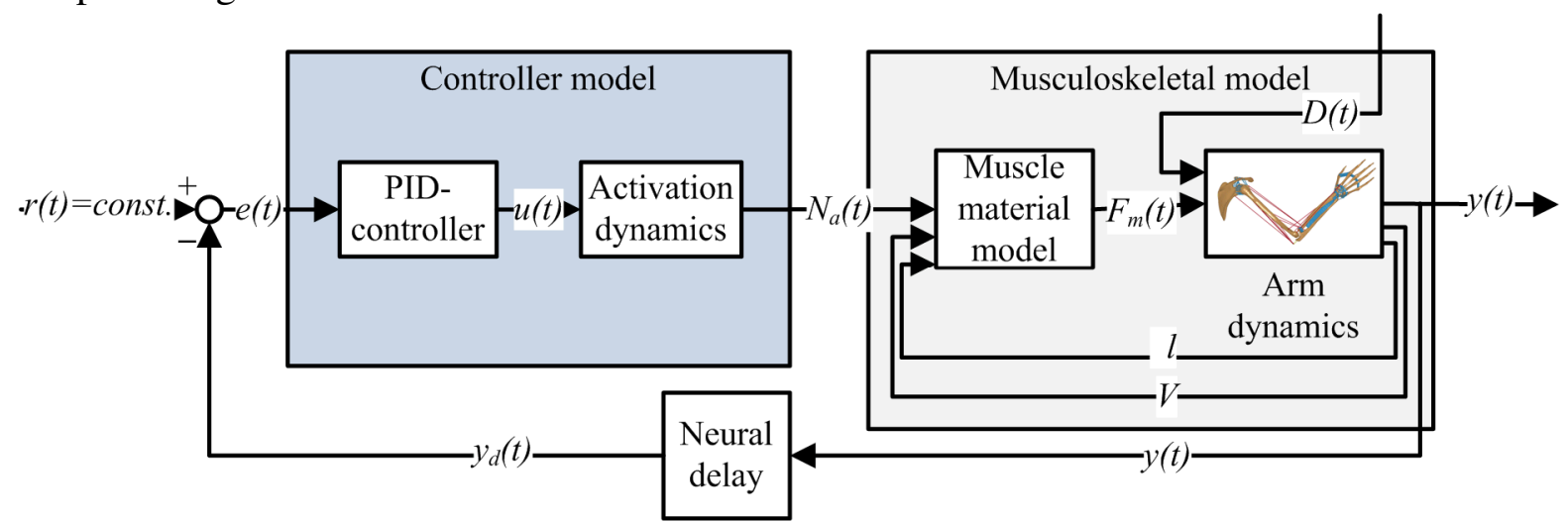

Figure 2. Illustration of how the controller model interacts with the musculoskeletal model in the FE solver. 


\subsection{Activation dynamics}

The muscle activation level $N_{a}(t)$ for the flexor and extensor muscle groups are given by activation dynamics models defined by two first order low pass filters in series (Winters and Stark 1985). The first filter is for an intermediate neural excitation level $N_{e}(t)$, driven by the signals $m_{f}$ and $m_{e}$, one for each muscle group. The second filter for the activation level $N_{a}(t)$ represents the contraction dynamics of the muscle and is mainly dependent on the calcium ion release from the sarcoplasmic reticulum, which is rate limiting for the muscle contraction (Winters and Stark 1987). Muscle activation, the calcium release, is faster than deactivation, the calcium absorption, which is why the time constant, $T_{n a}$, governing the contraction dynamics are split into two, $T_{\text {naa }}$ for activation and $T_{\text {nad }}$ for deactivation. The model time constants are based on the suggestions for upper arm muscles given by Winters and Stark (1985). Furthermore, the excitation level, $N_{e}(t)$, and activation level, $N_{a}(t)$, are saturated at a maximum equal to one while the lower limit is equal to a minimum activation of 0.005 which is added to $N_{e}(t)$.

$$
\begin{gathered}
T_{n e} \frac{d N e}{d t}=m_{f, e}-N_{e}(t), \\
T_{n a} \frac{d N_{a}}{d t}=N_{e}(t)-N_{a}(t) .
\end{gathered}
$$

\begin{tabular}{|c|c|c|c|c|}
\hline Parameter & Symbol & Unit & Flexors & Extensors \\
\hline Maximum isometric stress & $\sigma_{\max }$ & {$[\mathrm{MPa}]$} & 0.5 & 0.5 \\
\hline Maximum shortening velocity & $V_{\max }$ & {$\left[\mathrm{mm} \mathrm{s}^{-1}\right]$} & $5 l_{\text {opt }}$ & $5 l_{\text {opt }}$ \\
\hline$f_{v}$ constant, shortening & $C_{\text {short }}$ & {$[-]$} & 0.3 & 0.3 \\
\hline$f_{v}$ constant, lengthening & $C_{\text {leng }}$ & {$[-]$} & 0.005 & 0.005 \\
\hline$f_{v}$ constant, lengthening asymptote & $C_{m v l}$ & {$[-]$} & 1.35 & 1.25 \\
\hline Parallel element strain at $\sigma_{\max }$ & $P E_{\max }$ & {$[-]$} & 0.8 & 0.8 \\
\hline Parallel element constant & $C_{p e}$ & {$[-]$} & 6.15 & 3.0 \\
\hline Parallel element damping & $D$ & {$\left[\mathrm{Ns} \mathrm{m}^{-2}\right]$} & 4000 & 4000 \\
\hline Time constant, muscle activation & $T_{\text {naa }}$ & {$[\mathrm{ms}]$} & 5 & 5 \\
\hline Time constant, muscle deactivation & $T_{\text {nad }}$ & {$[\mathrm{ms}]$} & 30 & 30 \\
\hline Time constant, neural excitation & $T_{n e}$ & [ms] & 35 & 35 \\
\hline Neural delay & $T_{d e}$ & [ms] & 34 & 34 \\
\hline $\begin{array}{l}\text { Time constant, controller derivative } \\
\text { lowpass filter }\end{array}$ & $T_{f}$ & {$[\mathrm{~ms}]$} & 4.4 & 4.4 \\
\hline
\end{tabular}

Table 2. Parameters common for all muscles. 


\subsection{Volunteer experiments}

Volunteer experiments were conducted using the Arm Movement and Disturbance Analysis (ARMANDA) haptic manipulator (de Vlugt et al. 2003). The ARMANDA manipulator is a two-link robotic arm which can apply 2D force perturbations to the hand, as done by de Vlugt et al. (2006). The test subjects were positioned according to Figure 3, with the upper arm in the lateral direction at $90^{\circ}$ abduction, the elbow at a $90^{\circ}$ flexion angle, and the hand in a neutral position with the thumb pointing in the medial direction. The elbow was supported by a cord attached to the ceiling to prevent fatigue and motion of the shoulder. A cast was used to constrain motion of the wrist joint while pronation-supination of the lower arm was constrained by the setup. Hand force and position were measured. The elbow flexion angle was calculated from the hand position.

Eleven volunteers were tested (eight male, three female) twice in four different conditions:

- Experiments 1 and 2: A force pulse and the instruction to relax throughout the test;

- Experiments 3 and 4: A force pulse and the instruction to be prepared to resist the force pulse when applied;

- Experiments 5 and 6: Continuous random small force perturbations prior to a force pulse and the instruction to relax; and

- Experiments 7 and 8: Continuous random small force perturbations prior to a force pulse, and the instruction to resist the continuous perturbations and the pulse.

The force pulse was in the shape of a half sine wave with a duration of $80 \mathrm{~ms}$. Elbow flexion was induced by applying a lateral force, $F_{x}$, with a peak amplitude of $15 \mathrm{~N}$. Preliminary experiments showed that the $F_{x}$ pulse induced substantial shoulder anteflexion due to the complex impedance of the upper extremity (de Vlugt et al. 2006). This was resolved by applying an identical pulse, $F_{y}$, as illustrated in Figure 3. The continuous perturbations had an amplitude of $2.5 \mathrm{~N}$ with a bandwidth of $1-20 \mathrm{~Hz}$.

In this paper only results for one of the male test subjects (age 27, weight $70 \mathrm{~kg}$ and height $1.75 \mathrm{~m}$ ) are presented. This subject was chosen because of the relative closeness to the $50^{\text {th }}$ percentile male and that the results showed little variability between repetitions. Similar results were found in other subjects.

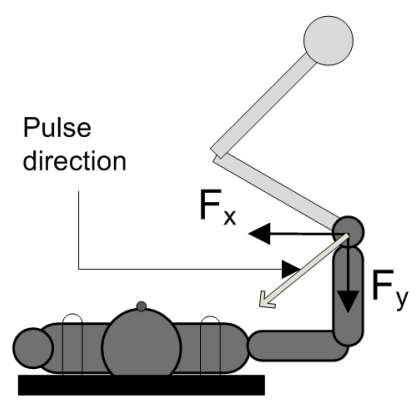

Figure 3. Volunteer test setup. 


\subsection{Simulations}

A total of 34 simulations with and without feedback control were carried out, see Table 3. Simulations 1-25 were made to evaluate the active and passive properties of the developed musculoskeletal model of the elbow with the revolute joint. Simulations 25-34 were made to evaluate the implemented feedback control structure with the revolute joint model and with the original sliding contact elbow joint.

In all of the simulations the overall posture of the upper extremity resembled a neutral driving position, see Figure 1. The lower arm and hand were in a neutral position with regard to pronation/supination of the elbow joint. The humerus position with respect to the shoulder girdle was slightly abducted and had approximately $30^{\circ}$ of shoulder flexion. The elbow flexion angle in the initial position was $88^{\circ}$. The humerus, scapula, and clavicula to which the modeled muscles are attached were fixed in space using nodal constraints.

In Simulations 1-25 the skeletal structures of the lower arm were merged into one rigid body. The prescribed motions in these simulations were applied to a rigid body connected with a spherical joint to the styloid process of the ulna. The joint force was recorded and used to derive the different moments in the simulations. For Simulations 29-32 the hand was merged into the lower arm rigid body.

The passive elbow joint stiffness of the model with the revolute joint was determined in simulations with a prescribed elbow joint motion, from $88^{\circ}$ to $140^{\circ}$ and back in Simulation 1 and to $25^{\circ}$ and back in Simulation 2. The applied motions were prescribed by sixth order polynomial functions. The polynomial functions prescribe zero angular acceleration and velocity at the beginning and end of the simulations, and zero velocity when the motion of the arm was reversed, see Figure 4 . The target velocity of the simulations was $18^{\circ} \mathrm{s}^{-1}$. Simulations 3 and 4 were identical to Simulations 1 and 2 except for the damping of the parallel elements (D) which was set to zero.

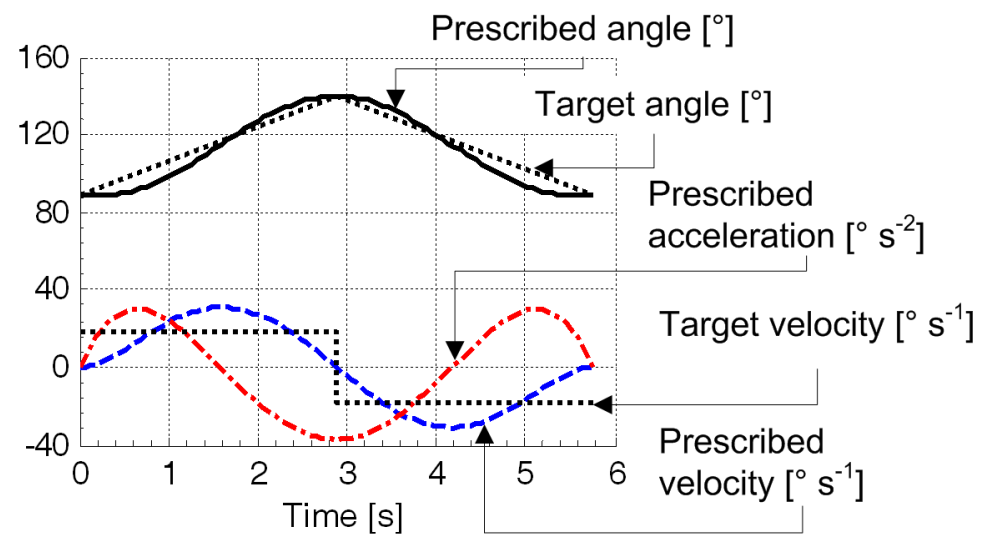

Figure 4. Prescribed motion for passive flexion moment test in Simulation 1 with target test velocity of $18^{\circ} \mathrm{s}^{-1}$. 
The maximum joint moments due to isometric muscle contraction were evaluated by making nine simulations (5-13). A rigid body connected to the styloid process of the ulna was prescribed to move to nine selected flexion angles, from $50^{\circ}$ to $135^{\circ}$. Once the arm was in position, the rigid body was fixed in space before maximum flexion and then extension activations were applied. The maximum isometric moments were computed from the rigid body joint forces.

The isokinetic joint moments at a $90^{\circ}$ flexion angle were evaluated with 12 simulations (14-25). In these simulations a rigid body connected to the styloid process of the ulna was prescribed a motion such that the arm was initially extended or flexed. From this position the rigid body was then prescribed a constant velocity, so that the arm moved past the $90^{\circ}$ position where the isokinetic moments at full activation were evaluated from the joint force between the arm and the rigid body. This test procedure is similar to the constant angle rate torques derived by Hortobágyi and Katch (1990).

To evaluate how well the model developed could maintain its posture to gravity, simulations were performed with the two models, intact elbow joint and revolute joint. At the beginning of the simulation gravity was instantaneously applied. A co-contraction increase of $5.0 \%$ extensor activation was used. This corresponds to a calculated flexor activation increase of $2.9 \%$. In Simulation 26, the controller gains were set to zero to simulate the passive model response without feedback. The controller parameters used in Simulations 27 and 28 were derived using engineering judgment.

In Simulations 29-34 of the volunteer experiments, the test equipment was represented by a rigid body with a mass of $3 \mathrm{~kg}$ representing the virtual mass of the ARMANDA manipulator handle (de Vlugt et al. 2003). The rigid body was attached to the hand by a spring element with a linear stiffness of $9.36 \mathrm{kN} \mathrm{m}^{-1}$, representing the hand to handle contact stiffness (de Vlugt et al. 2006). The inertia of the lower arm was increased by the addition of a $0.4 \mathrm{~kg}$ nodal point mass to the hand to better match the force amplitude in the experiments. The same co-contraction activations as in Simulation 26-29 were used.

During the first $80 \mathrm{~ms}$, the experimentally recorded movement is prescribed to the rigid body representing the handle of the test rig. After $80 \mathrm{~ms}$, all constraints are removed from the rigid body. Simulations 29-32 were performed with a rigid lower arm and revolute joint for the elbow. Simulation 33 was performed with a deformable lower arm and Simulation 34 with a deformable lower arm and the sliding contact elbow joint. 
Table 3. Simulation matrix. $[$ CC. $=$ Co-Contraction; Con. $=$ Contact; Def. $=$ Deformable; Rev. $=$ Revolute $]$.

\begin{tabular}{|c|c|c|c|c|c|c|c|c|c|}
\hline Sim. & Load case & $\begin{array}{l}\text { Sim. } \\
\text { time } \\
{[\mathrm{s}]}\end{array}$ & $\begin{array}{l}\text { Lower } \\
\text { arm }\end{array}$ & $\begin{array}{l}\text { Elbow } \\
\text { joint }\end{array}$ & $\begin{array}{l}\text { Added } \\
\text { mass } \\
{[\mathrm{kg}]}\end{array}$ & $\begin{array}{l}\text { CC. } \\
{[\%]}\end{array}$ & $\begin{array}{l}\mathrm{K}_{\mathrm{p}} \\
{\left[\mathrm{Nm} \mathrm{rad}^{-1}\right]}\end{array}$ & $\begin{array}{l}\mathrm{K}_{\mathrm{i}} \\
{\left[\mathrm{Nm} \mathrm{rad}^{-1} \mathrm{~s}^{-1}\right]}\end{array}$ & $\begin{array}{l}\mathrm{K}_{\mathrm{d}} \\
{\left[\mathrm{Nms} \mathrm{rad}^{-1}\right]}\end{array}$ \\
\hline 1 & Passive flexion & 5.76 & Rigid & Rev. & 0 & 0 & $\mathrm{n} / \mathrm{a}$ & $\mathrm{n} / \mathrm{a}$ & $\mathrm{n} / \mathrm{a}$ \\
\hline 2 & Passive extension & 6.24 & Rigid & Rev. & 0 & 0 & $\mathrm{n} / \mathrm{a}$ & $\mathrm{n} / \mathrm{a}$ & $\mathrm{n} / \mathrm{a}$ \\
\hline 3 & Passive flexion, $D=0$ & 5.76 & Rigid & Rev. & 0 & 0 & $\mathrm{n} / \mathrm{a}$ & $\mathrm{n} / \mathrm{a}$ & $\mathrm{n} / \mathrm{a}$ \\
\hline 4 & Passive extension, $D=0$ & 6.24 & Rigid & Rev. & 0 & 0 & $\mathrm{n} / \mathrm{a}$ & $\mathrm{n} / \mathrm{a}$ & $\mathrm{n} / \mathrm{a}$ \\
\hline 5 & Max. isometric moment, $50^{\circ}$ & 0.8 & Rigid & Rev. & 0 & 0 & $\mathrm{n} / \mathrm{a}$ & $\mathrm{n} / \mathrm{a}$ & $\mathrm{n} / \mathrm{a}$ \\
\hline 6 & Max. isometric moment, $60^{\circ}$ & 0.8 & Rigid & Rev. & 0 & 0 & $\mathrm{n} / \mathrm{a}$ & $\mathrm{n} / \mathrm{a}$ & $\mathrm{n} / \mathrm{a}$ \\
\hline 7 & Max. isometric moment, $70^{\circ}$ & 0.8 & Rigid & Rev. & 0 & 0 & $\mathrm{n} / \mathrm{a}$ & $\mathrm{n} / \mathrm{a}$ & $\mathrm{n} / \mathrm{a}$ \\
\hline 8 & Max. isometric moment, $80^{\circ}$ & 0.8 & Rigid & Rev. & 0 & 0 & $\mathrm{n} / \mathrm{a}$ & $\mathrm{n} / \mathrm{a}$ & $\mathrm{n} / \mathrm{a}$ \\
\hline 9 & Max. isometric moment, $90^{\circ}$ & 0.8 & Rigid & Rev. & 0 & 0 & $\mathrm{n} / \mathrm{a}$ & $\mathrm{n} / \mathrm{a}$ & $\mathrm{n} / \mathrm{a}$ \\
\hline 10 & Max. isometric moment, $100^{\circ}$ & 0.8 & Rigid & Rev. & 0 & 0 & $\mathrm{n} / \mathrm{a}$ & $\mathrm{n} / \mathrm{a}$ & $\mathrm{n} / \mathrm{a}$ \\
\hline 11 & Max. isometric moment, $110^{\circ}$ & 0.8 & Rigid & Rev. & 0 & 0 & $\mathrm{n} / \mathrm{a}$ & $\mathrm{n} / \mathrm{a}$ & $\mathrm{n} / \mathrm{a}$ \\
\hline 12 & Max. isometric moment, $120^{\circ}$ & 0.8 & Rigid & Rev. & 0 & 0 & $\mathrm{n} / \mathrm{a}$ & $\mathrm{n} / \mathrm{a}$ & $\mathrm{n} / \mathrm{a}$ \\
\hline 13 & Max. isometric moment, $130^{\circ}$ & 0.8 & Rigid & Rev. & 0 & 0 & $\mathrm{n} / \mathrm{a}$ & $\mathrm{n} / \mathrm{a}$ & $\mathrm{n} / \mathrm{a}$ \\
\hline 14 & Concentric flexion, $0.5 \mathrm{rad} \mathrm{s}^{-1}$ & 2.25 & Rigid & Rev. & 0 & 0 & $\mathrm{n} / \mathrm{a}$ & $\mathrm{n} / \mathrm{a}$ & $\mathrm{n} / \mathrm{a}$ \\
\hline 15 & Concentric flexion, $1.5 \mathrm{rad} \mathrm{s}^{-1}$ & 0.92 & Rigid & Rev. & 0 & 0 & $\mathrm{n} / \mathrm{a}$ & $\mathrm{n} / \mathrm{a}$ & $\mathrm{n} / \mathrm{a}$ \\
\hline 16 & Concentric flexion, $2 \mathrm{rad} \mathrm{s}^{-1}$ & 0.75 & Rigid & Rev. & 0 & 0 & $\mathrm{n} / \mathrm{a}$ & $\mathrm{n} / \mathrm{a}$ & $\mathrm{n} / \mathrm{a}$ \\
\hline 17 & Eccentric flexion, $0.5 \mathrm{rad} \mathrm{s}^{-1}$ & 2.25 & Rigid & Rev. & 0 & 0 & $\mathrm{n} / \mathrm{a}$ & $\mathrm{n} / \mathrm{a}$ & $\mathrm{n} / \mathrm{a}$ \\
\hline 18 & Eccentric flexion, $1.5 \mathrm{rad} \mathrm{s}^{-1}$ & 0.92 & Rigid & Rev. & 0 & 0 & $\mathrm{n} / \mathrm{a}$ & $\mathrm{n} / \mathrm{a}$ & $\mathrm{n} / \mathrm{a}$ \\
\hline 19 & Eccentric flexion, $2 \mathrm{rad} \mathrm{s}^{-1}$ & 0.75 & Rigid & Rev. & 0 & 0 & $\mathrm{n} / \mathrm{a}$ & $\mathrm{n} / \mathrm{a}$ & $\mathrm{n} / \mathrm{a}$ \\
\hline 20 & Concentric extension, $0.5 \mathrm{rad} \mathrm{s}^{-1}$ & 2.25 & Rigid & Rev. & 0 & 0 & n/a & $\mathrm{n} / \mathrm{a}$ & $\mathrm{n} / \mathrm{a}$ \\
\hline 21 & Concentric extension, $1.5 \mathrm{rad} \mathrm{s}^{-1}$ & 0.92 & Rigid & Rev. & 0 & 0 & $\mathrm{n} / \mathrm{a}$ & $\mathrm{n} / \mathrm{a}$ & $\mathrm{n} / \mathrm{a}$ \\
\hline 22 & Concentric extension, $2 \mathrm{rad} \mathrm{s}^{-1}$ & 0.75 & Rigid & Rev. & 0 & 0 & $\mathrm{n} / \mathrm{a}$ & $\mathrm{n} / \mathrm{a}$ & $\mathrm{n} / \mathrm{a}$ \\
\hline 23 & Eccentric extension, $0.5 \mathrm{rad} \mathrm{s}^{-1}$ & 2.25 & Rigid & Rev. & 0 & 0 & $\mathrm{n} / \mathrm{a}$ & $\mathrm{n} / \mathrm{a}$ & $\mathrm{n} / \mathrm{a}$ \\
\hline 24 & Eccentric extension, $1.5 \mathrm{rad} \mathrm{s}^{-1}$ & 0.92 & Rigid & Rev. & 0 & 0 & $\mathrm{n} / \mathrm{a}$ & $\mathrm{n} / \mathrm{a}$ & $\mathrm{n} / \mathrm{a}$ \\
\hline 25 & Eccentric extension, $2 \mathrm{rad} \mathrm{s}^{-1}$ & 0.75 & Rigid & Rev. & 0 & 0 & $\mathrm{n} / \mathrm{a}$ & $\mathrm{n} / \mathrm{a}$ & $\mathrm{n} / \mathrm{a}$ \\
\hline 26 & Stepwise applied gravity & 2 & Def. & Rev. & 0 & 5.5 & 0 & 0 & 0 \\
\hline 27 & Stepwise applied gravity & 2 & Def. & Rev. & 0 & 5.5 & 34 & 97 & 1.5 \\
\hline 28 & Stepwise applied gravity & 5 & Def. & Con. & 0 & 5.5 & 20 & 10 & 1 \\
\hline 29 & Volunteer Exp. 1 \& 2 & 2 & Rigid & Rev. & 0.4 & 5.5 & 2.5 & 0 & 0 \\
\hline 30 & Volunteer Exp. 3 \& 4 & 2 & Rigid & Rev. & 0.4 & 5.5 & 15 & 0 & 1.5 \\
\hline 31 & Volunteer Exp. 5 \& 6 & 2 & Rigid & Rev. & 0.4 & 5.5 & 8 & 0 & 2.5 \\
\hline 32 & Volunteer Exp. 7 \& 8 & 2 & Rigid & Rev. & 0.4 & 5.5 & 23.7 & 0 & 5.3 \\
\hline 33 & Volunteer Exp. $7 \& 8$ & 2 & Def. & Rev. & 0.4 & 5.5 & 23.7 & 0 & 5.3 \\
\hline 34 & Volunteer Exp. $7 \& 8$ & 2 & Def. & Con. & 0.4 & 5.5 & 23.7 & 0 & 5.3 \\
\hline
\end{tabular}




\section{Results}

Results are presented for Simulations 1-4 in Section 3.1, Simulations 5-25 in Section 3.2, Simulations 26-28 in Section 3.3, and Simulations 29-34 in Section 3.4.

\subsection{Passive properties}

The results from Simulations 1 and 2 are shown in Figure 5 and compared with experimental data (Hayes and Hatze 1977; Wiegner and Watts 1986; Howell et al. 1993). The passive stiffness of the elbow revolute joint without any muscle activation is approximately $1.1 \mathrm{Nm}$ $\operatorname{rad}^{-1}$ at the neutral position which is at a flexion angle of $92^{\circ}$. The muscle elements contribute $0.5 \mathrm{Nm} \mathrm{rad}{ }^{-1}$ to the passive elbow stiffness. At $26^{\circ}$ and $128^{\circ}$ flexion angles there is a rapid increase in the elbow stiffness due to the stiffness of the rigid body joint. The passive moment characteristics in Figure 5 exhibit some hysteresis. Simulations 3 and 4 show that this hysteresis is due to the muscular damping (results not plotted).

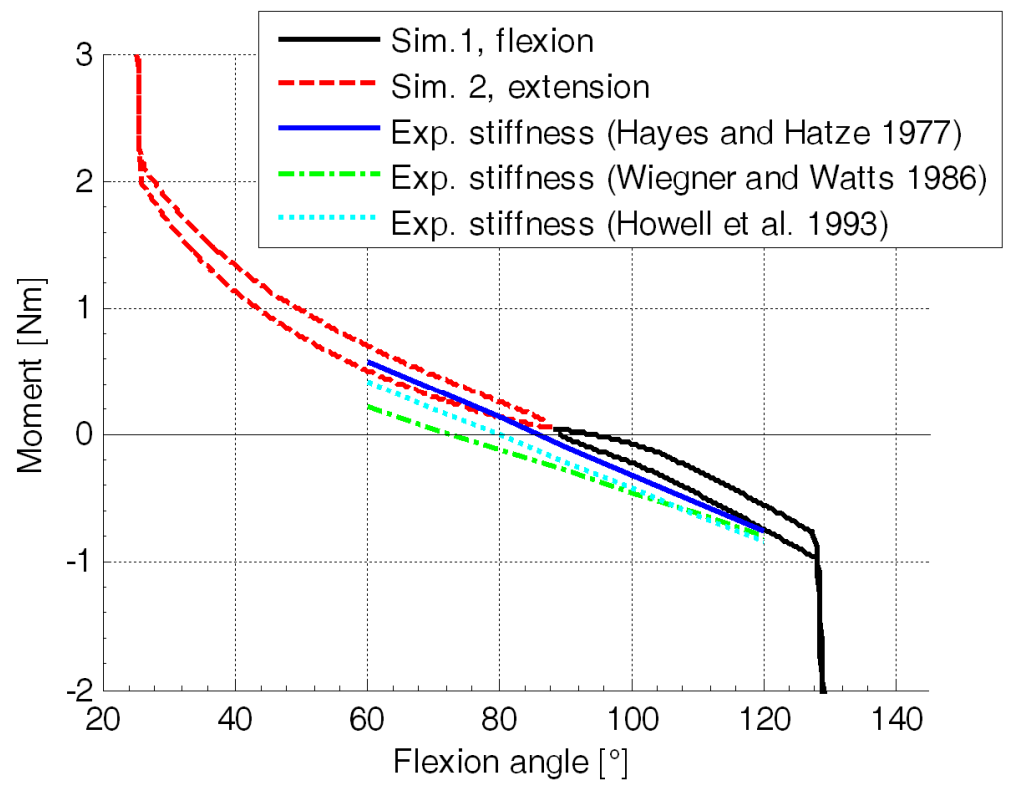

Figure 5. The passive elbow joint moment at $18^{\circ} \mathrm{s}^{-1}$ target test velocity in flexion (dashed line) and extension (solid line) from Simulations 1 and 2 and from human test subjects in quasi-static tests (solid, dash-dot, and dotted lines) (Hayes and Hatze 1977; Wiegner and Watts 1986; Howell et al. 1993). [Sim. = Simulation].

\subsection{Active properties}

Simulations 5-13 show that the maximum isometric flexion moment of the model is $68.8 \mathrm{Nm}$ at a $100^{\circ}$ flexion angle, while the maximum isometric moment in extension is $38.6 \mathrm{Nm}$ at $90^{\circ}$. Figure 6 also includes experimental data on the average maximum isometric moments of four male test subjects between 24 and 37 years of age (Buchannan et al. 1998). The isometric moments of the model have lower amplitude than the experimental data. However, the curve shapes are similar and the maximum values occur at the same joint angles.

Isokinetic moments were determined from Simulations 14-25 and compared with the average of 40 male test subjects (Hortobágyi and Katch 1990), see Figure 7. The normalized isokinetic moments of the model correspond quite well to the experimental data. The absolute flexion isokinetic moments are also comparable. The extension isokinetic moments, on the other hand, show a larger difference and the model is considerably weaker than the experimentally tested subjects. 


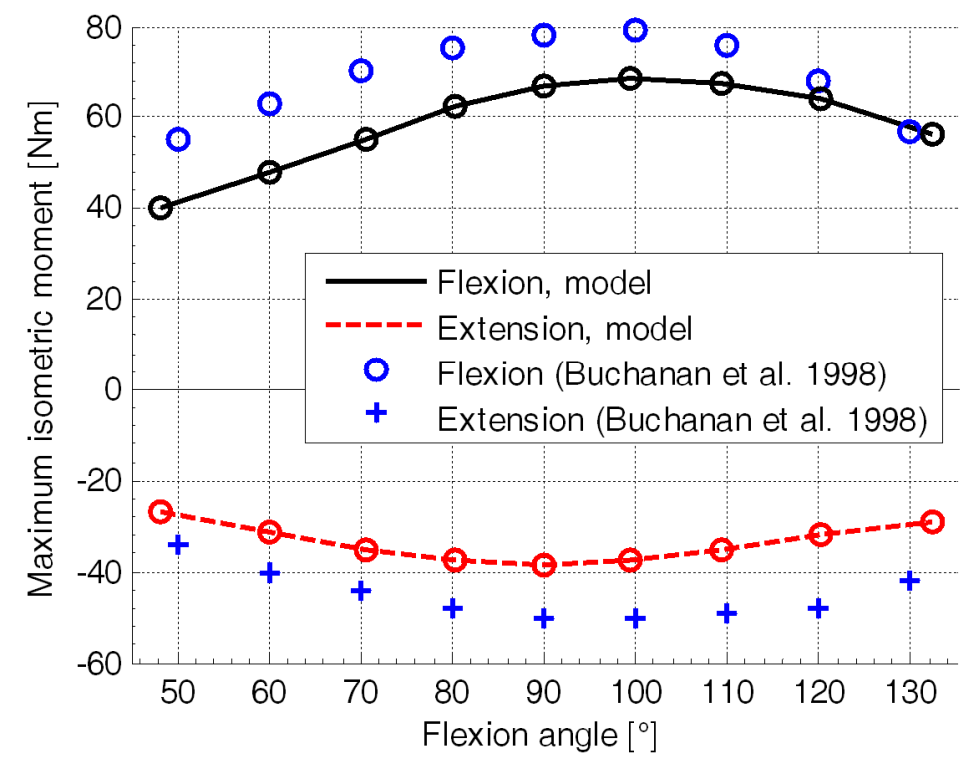

Figure 6. Maximum isometric moments from Simulations 5-13 in flexion (solid line), extension (dashed line) and experimental data (circles and crosses) for human subjects (Buchannan et al. 1998).
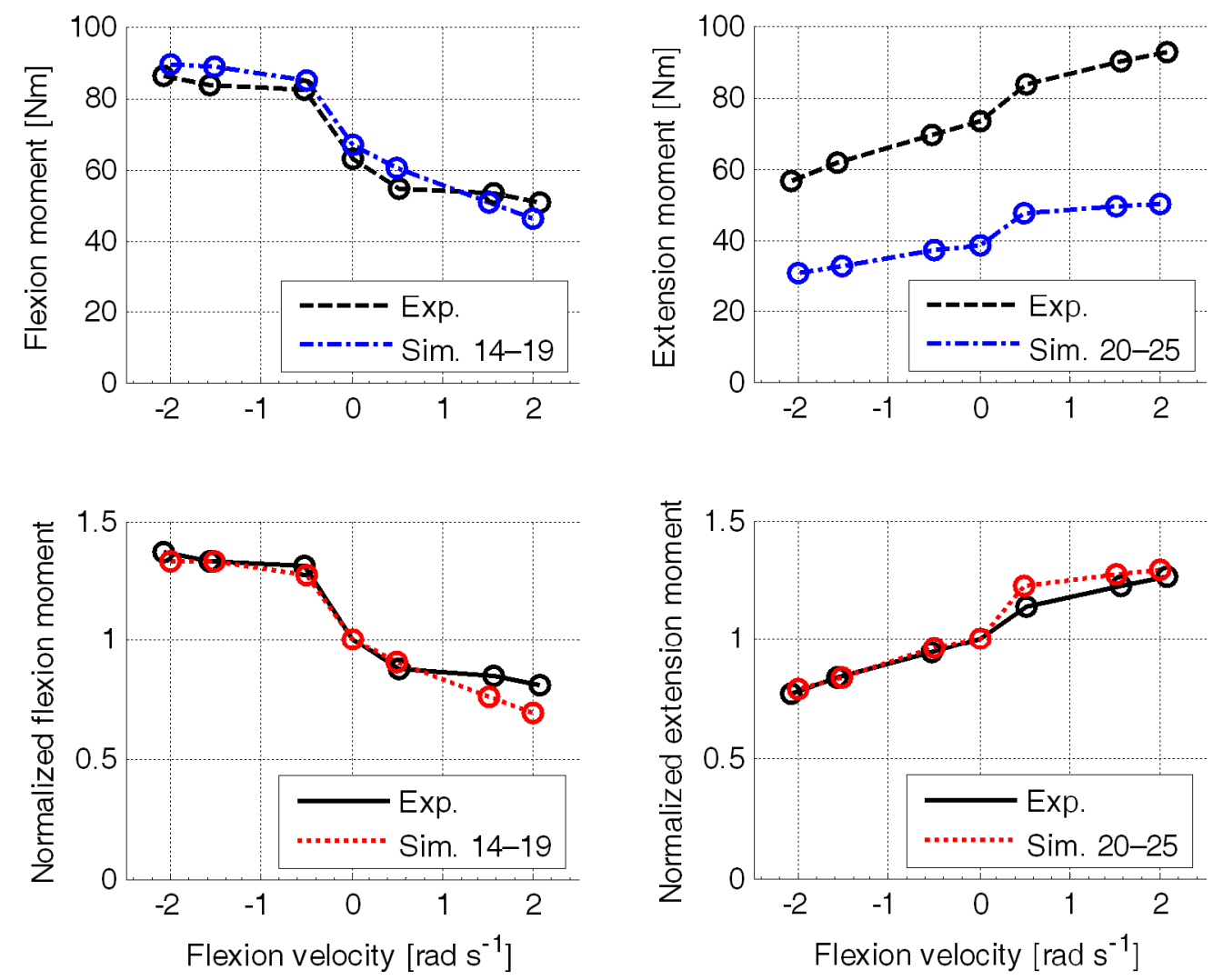

Figure 7. Isokinetic moments (dash-dot lines) and normalized isokinetic moments (dotted lines) from Simulation 14-25; average isokinetic moments (dashed lines) and normalized isokinetic moments (solid lines) of human subjects (Hortobágyi and Katch 1990). 


\subsection{Posture maintenance}

The elbow angles, resulting after gravity was applied, in Simulations 26 and 27 are shown in Figure 8. The model with the PID controller (Simulation 27) can maintain its posture as gravity is applied, but the other model cannot. The uncontrolled model (Simulation 26) extends to the limit determined by the passive joint stiffness. The model with the PID controller (Simulation 27) reaches a minimum of $85.6^{\circ}$ flexion angle at $125 \mathrm{~ms}$ and then rebounds towards the reference value as the flexor activation level increases. A small overshoot in the response is visible; for the next drop below the reference value, there is a minimum flexion angle of $87.5^{\circ}$ at $400 \mathrm{~ms}$. After that the model approaches the reference value more slowly and reaches $88^{\circ}$ at $900 \mathrm{~ms}$.

In the initial phase, when the flexion angle increases, the flexor muscles are stretched eccentrically. This can be seen in the force for the flexor muscles in Figure 9, where there is an increase in flexor force before the $34 \mathrm{~ms}$ neural delay has passed and the activation starts to increase to counteract the applied loading. Accordingly, the extensor elements are allowed to shorten concentrically and show a small instant force decrease before the extensor activation is decreased.

In Simulation 28 with the sliding contact elbow joint, the model also counteracts the disturbance and slowly returns to the initial position, but the lower arm also has a $10^{\circ}$ motion in the lateral direction. In Simulation 28 lower controller gains had to be used to than compared with Simulation 27 to ensure a stable response, and thus the time it takes for the arm to return to the reference position is significantly longer, as seen in Figure 8.
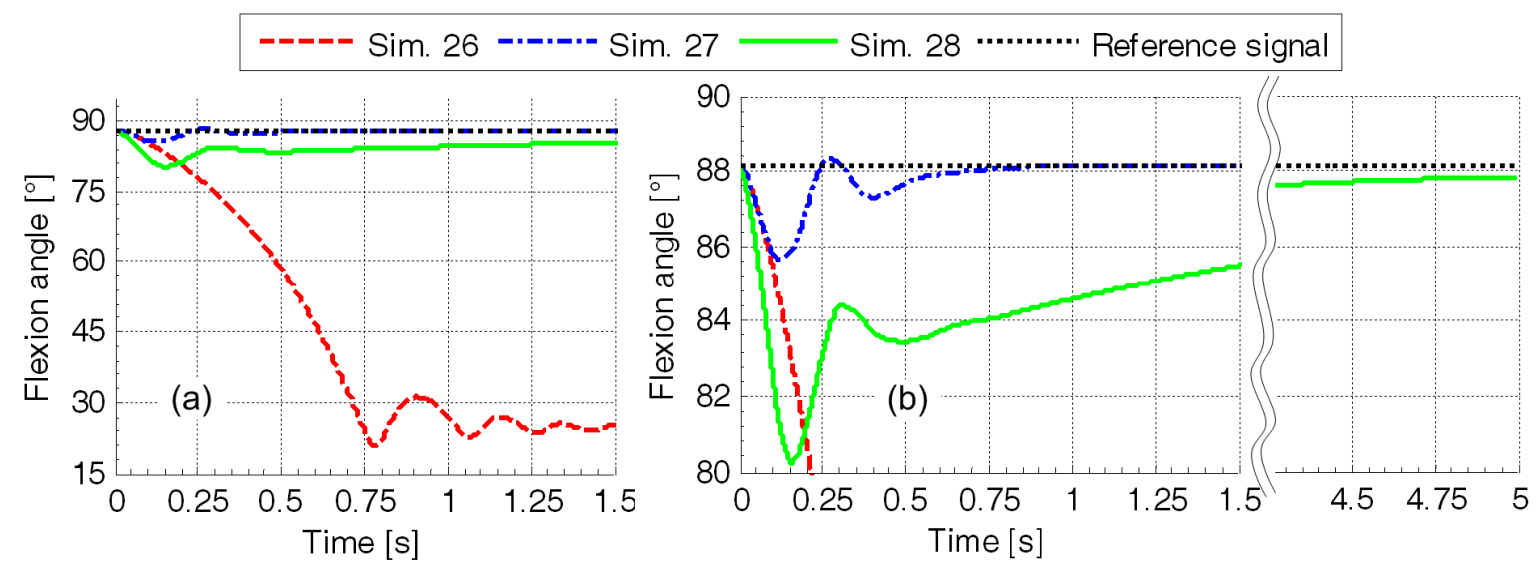

Figure 8. The resulting elbow angle due to gravity in Simulation 26 without feedback (dashed line), in Simulation 27 with feedback (dash-dot line), and in Simulation 28 with feedback and sliding contact joint (solid line). 


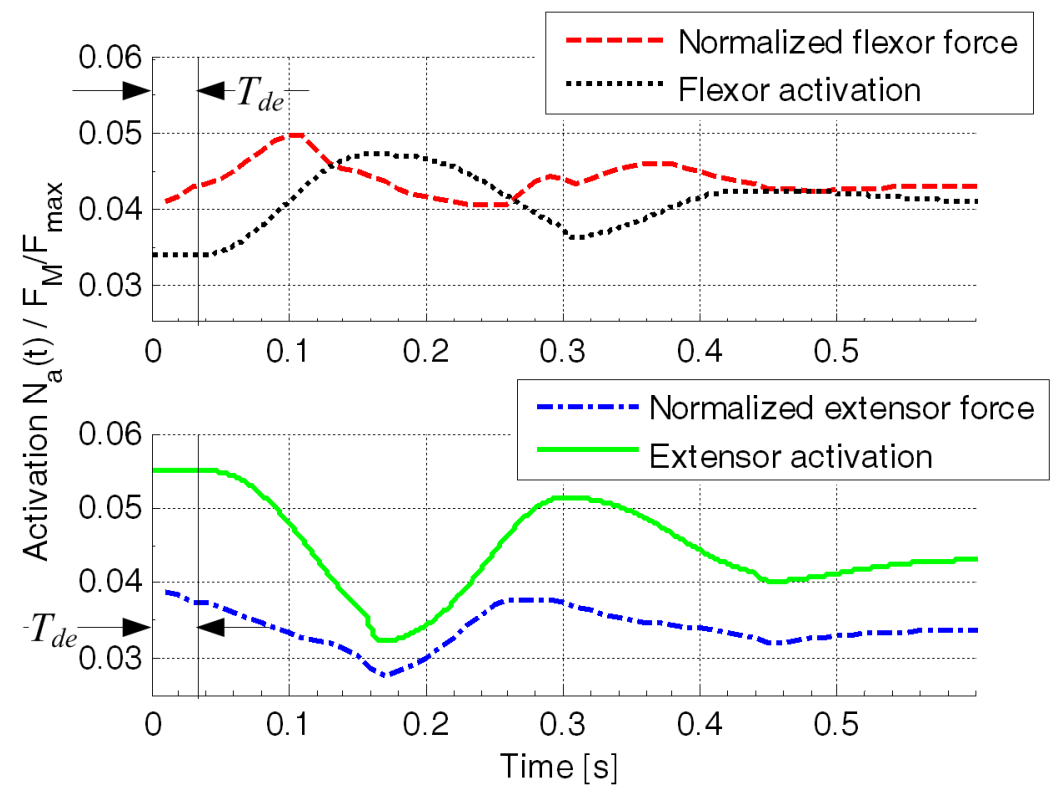

Figure 9. Normalized forces and activation levels for the flexor (top) and extensor (bottom) muscles in Simulation 27 with gravity.

\subsection{Volunteer experiments}

The force pulses resulting in Simulations 29-32 are compared with the volunteer experiments, see Figure 10. All volunteer tests had similar force time histories during the first $80 \mathrm{~ms}$, hence only Volunteer Experiments 1 and 2 are shown.

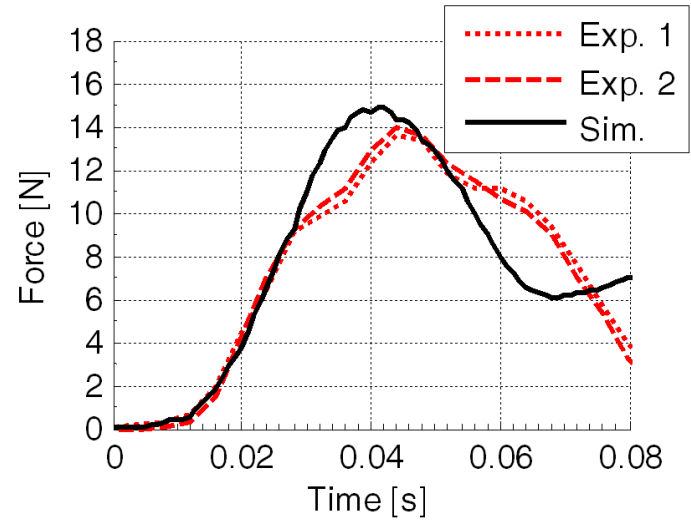

Figure 10. Force pulse $\left(F_{x}\right)$ for the Volunteer Experiments 1 and 2 (dashed lines) and in Simulations 29-32 (solid line). 
The characteristics of the different instructions given to the volunteers are captured by variation of the controller parameters in the simulation model. In Simulation 29 the model matches the response of the relax instruction in Volunteer Experiments 1 and 2 with a low position gain of $2.5 \mathrm{Nm} \mathrm{rad}^{-1}$ (Figure 11a and b). In Volunteer Experiment 3 and 4, with the instruction to be prepared to resist, a faster and more active response is seen (Figure 11c and d). This behavior is captured by the model in Simulation 30 with an increase of the position gain to $15 \mathrm{Nm} \mathrm{rad}^{-1}$ and the inclusion of a velocity gain of $1.5 \mathrm{Nms} \mathrm{rad}^{-1}$. For the continuous perturbations with relax instructions (Volunteer Experiment 5 and 6) the test subject's initial position deviates from the prescribed $90^{\circ}$ elbow flexion angle due to the continuous perturbation before the force pulse (Figure 11e and $\mathrm{f}$ ). The general behavior of the test condition is captured by a position gain of $8 \mathrm{Nm} \mathrm{rad}^{-1}$ and a velocity gain of $2.5 \mathrm{Nms} \mathrm{rad}^{-1}$ used in Simulation 31. Finally, Simulation 32 of Volunteer Experiment 7 and 8 with continuous perturbations and the instruction to resist was simulated with a position gain of 23.7 $\mathrm{Nm} \mathrm{rad}{ }^{-1}$ and a velocity gain of $5.3 \mathrm{Nms} \mathrm{rad}^{-1}$ (Figure $11 \mathrm{~g}$ and $\mathrm{h}$ ). The controller parameters used for Simulation 32 were estimated by de Vlugt et al. (2006) using linear methods for continuous perturbation tests but without the force pulse used for the volunteer tests in this study.

The model with the revolute joint and deformable bones in Simulation 33 is compared to Simulation 32 in Figure 12. Although the amplitude of the responses is very similar for the two simulations, in Simulation 33 a larger phase lag is present and the response is delayed for about $20 \mathrm{~ms}$ after the initial peak angle. Also, Simulation 33 showed an increase in required CPU time of $38 \%$ compared with Simulation 32. Simulation 34 with the original sliding contact elbow joint has a slightly more damped response than Simulation 32 and 33, as can be seen in Figure 12. Just as in the case of Simulation 28 the arm shows a $10^{\circ}$ movement of the elbow joint in a plane transverse to the flexion/extension rotation plane. The arm is stabilized but a $2^{\circ}$ flexion angle steady state error is present due to the out of plane movement and absence of integral gain in this simulation. 

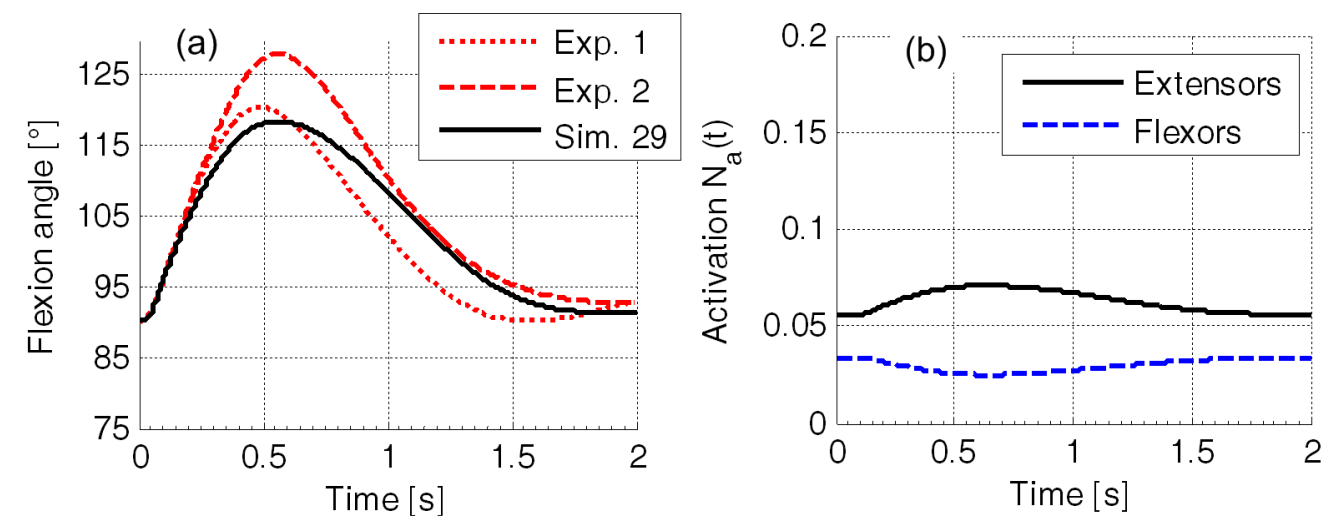

(c)
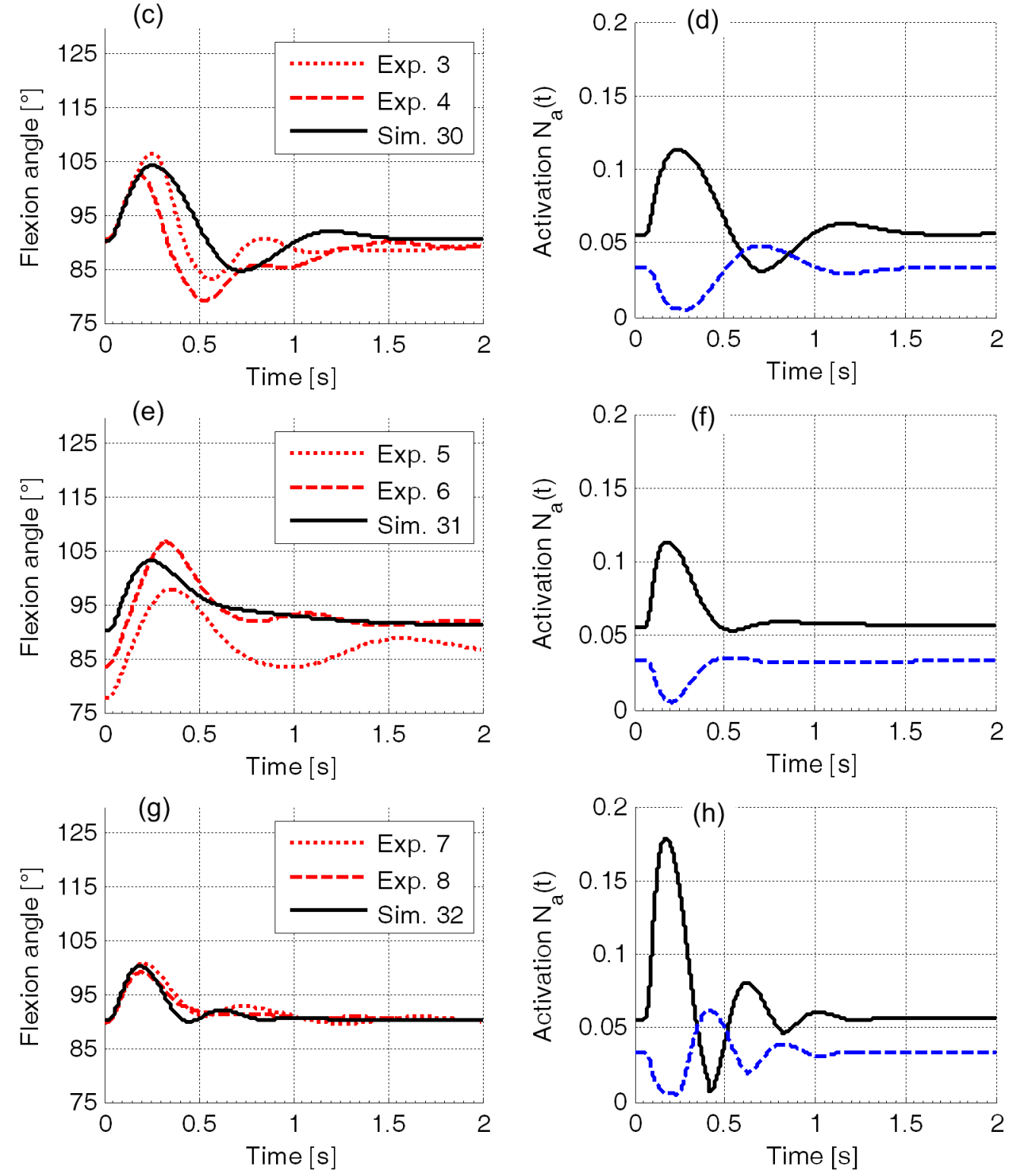

Figure 11. Resulting elbow flexion angles (left) and activation levels (right) in response to force pulses in Simulations 29-32 (solid line) compared with the volunteer experiments (dashed lines). 


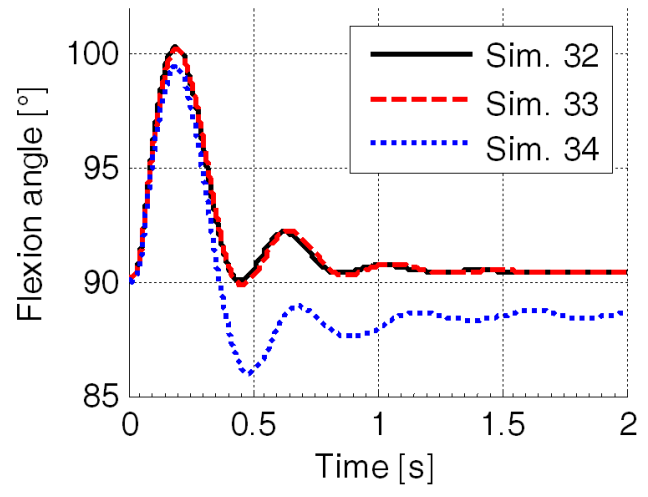

Figure 12. Comparison of the resulting elbow flexion angles in Simulation 32-34.

\section{Discussion}

This study has successfully implemented feedback control of a muscle material model in an FE model of the human arm. First, muscle elements were added to an existing model of the right arm and shoulder complex, according to anatomical literature. A Hill-type muscle material model was used and material parameters were fitted according to literature. Then, the passive and active muscle properties were assessed by comparing the model response with experimental data. The model developed has comparable characteristics for the passive elbow joint stiffness as well as the isometric strength within the interval of 50-125 flexion angles, while the absolute isokinetic strength in extension differs from experimental results. Second, feedback control parameters were determined so that the model could maintain its posture when gravity was applied. Then, the difference in the responses of a volunteer subject, instructed to relax or to resist an impact, was captured in simulations with different sets of feedback control parameters. Finally, the challenges with a sliding contact joint were assessed by comparison with a revolute joint for the elbow. The positive results of this study, where volunteer responses were captured, indicate that it is possible to simulate, with an FE HBM, the active human response that can be expected in the pre-crash phase. The difference in occupant responses could be captured with different sets of controller parameters for an implemented feedback controller model. This is important when the occupant awareness of an impending accident plays a major role in the response.

Cappon et al. (2007) stabilized the spine of a MB HBM using PID controlled toque actuators on each vertebra. They concluded in their study that the next step in the modeling work to achieve a more human-like modeling of the active human response would be to implement line muscle elements instead of torque actuators. The present study confirmed the feasibility of implementing active control of such elements in an FE HBM for the elbow joint. Fraga et al. (2009) used line muscle elements to stabilize the head of a motorcycle rider, but in their study the effect of neural delay and activation dynamics was omitted. The present study reproduced the human response to force pulse perturbations with a model that includes both a neural delay and non-linear activation dynamics. The study in this paper contributes to the active control of HBM in that it includes a more detailed modeling approach of the neuromuscular system and also enables the modeling of active human behavior in an FE environment. 


\subsection{The musculoskeletal model}

The muscle elements were implemented as single line elements without any series elastic elements representing the tendons or other connective tissues. Including the series elastic element of the Hill model has previously been reported to cause problems with numerical stability in an FE environment (Wittek and Kajzer 1997; Hedenstierna 2008). A reason for this instability, which was observed in the current study as well as by Wittek and Kajzer (1997), is that when the line muscle elements are coupled to a deformable structure, such as a tendon element, the nodes of the muscle element can vibrate. The force level of the muscle element can then vary rapidly, due to the large difference in stress when changing from eccentric to concentric contraction, which in turn increases the vibration of the element nodes. Initially, even without tendon elements the model with deformable bones displayed such numerical instabilities. This was solved by increasing the density of the muscle elements since, in the THUMS ${ }^{\circledR}$, all muscle mass is included in the solid elements representing the soft tissues of the arm. The added mass needed to limit the nodal vibration was insignificant when compared with the total mass of the soft tissues.

The optimum muscle lengths were selected by matching available isometric data; the maximum shortening velocity was selected by matching isokinetic data. Data presented by An et al. (1981) show that the actual muscle fiber length should range from $75 \%$ of the total muscle length (for the brachialis muscle) to $30 \%$ of the total muscle length (for the medial head of triceps). In the present study, the length of the muscle elements includes the full musculotendon length. Therefore, the optimum model muscle lengths are on average about $50 \%$ longer than actual optimum fiber length. This was accounted for in the choice of the maximum shortening velocity, $V_{\max }$. Zajac (1989) suggests a use of $V_{\max }=10 l_{\text {opt }}$, but as the optimum lengths of the model are approximately $50 \%$ too large, $V_{\max }=5 l_{\text {opt }}$ was chosen.

To find an overall model strength comparable to volunteer tests, others have previously scaled the maximum contractile stress (Holzbaur et al. 2005; van der Horst 2002). However, scaling of the PCSA should be a more correct method as the PSCA values reported in the literature are often based on studies with cadavers. It was shown by Chancey et al. (2003) that the muscle volume of young $50^{\text {th }}$ percentile male volunteers is $62 \%$ larger than muscle volumes derived from cadavers. Hence, it can be assumed that the $60 \%$ increase of the PCSA used in this study is realistic. A comparison of the maximum isometric moments in flexion and extension of the model and the experimental data (Buchannan et al. 1998) shows that the human test subjects have $120 \%$ of the model strength in flexion and $130 \%$ in extension, even with the $60 \%$ PCSA increase in the model. This difference was not adjusted, since only a $60 \%$ increase of PCSA could be motivated by the study of Chancey et al. (2003). 


\subsection{The controller model}

If the closed loop model in the initial state has no co-contraction, the closed loop characteristics are such that only very low controller gains give a stable response to a perturbation. This has the effect that the performance of the model, i.e. the ability to return to the reference state after a perturbation, is poor. The main reason for this appears to be the influence of the delay in the control loop, which is well known to have such an effect. This effect is reduced by an increase in the initial co-contraction of the muscles that provides a damping response when the muscles are stretched eccentrically and helps to stabilize the feedback loop. In other studies considerable co-contraction levels resulting in a relevant intrinsic joint stiffness and damping have been reported (de Vlugt et al. 2006). However, to the best of our knowledge, absolute levels as a percentage of maximum voluntary contractions have not been reported. There is a need for such data to assess the feasibility of the cocontraction level used.

One of the differences for the feedback control loop when using an FE HBM compared to a MB HBM is the elasticity of the skeletal structures. In simulations with deformable bones a small increase in phase lag from neural input to segment acceleration was seen compared to simulations with rigid bones. This indicates that a deformable FE model could be more difficult to control.

The use of a revolute joint, to replace the contact based elbow joint of the original model, ensured pure 1D flexion-extension motions of the lower arm. This provided a well defined elbow joint angle for the controller model. It is possible to use the same controller model with the contact based elbow joint, which is a typical requirement for an FE HBM. However, a sliding contact joint provided some additional challenges, because the 3D joint motions were controlled using a 1D reference signal and because the sliding contact joint gives a considerable increase in phase lag, that can be seen in open loop simulations. For the posture maintenance simulation, lower feedback gains had to be used. It can be concluded that much care should be taken to ensure that biofidelic contact based joints, which gives well defined motions, are implemented in FE HBM as this will enable the implementation of feedback control.

The total rotational inertia of the lower arm around the elbow joint defined with the $0.4 \mathrm{~kg}$ added mass is $760 \mathrm{~kg} \mathrm{~cm}^{2}$, while the original rotational inertia of the THUMS ${ }^{\circledR}$ lower arm is $324 \mathrm{~kg} \mathrm{~cm}^{2}$. Veeger et al. (1997) have reported the mass and inertia of the upper extremities of five male subjects (age 48-81, weight 62-98 kg). The average rotational inertia around the elbow joint for these subjects was calculated to $645 \mathrm{~kg} \mathrm{~cm}^{2}$ in the present study. Hence, the rotational inertia used for Simulations 29-34 is somewhat larger than what was found by Veeger et al. (1997). The original rotational inertia and mass of the THUMS ${ }^{\circledR}$ lower arm is lower than those of actual human subjects, probably due to the absence of soft tissues in the hand of the model..

This study shows that it possible to reproduce the variations in human response to low level impact forces through variation of the controller parameters. Furthermore, the feedback gains estimated by using continuous perturbations and linear methods appear to be valid also for low level impact loading in a non-linear model of the elbow joint. 


\section{Conclusions}

It is possible to use feedback control of a non-linear musculoskeletal model in an FE environment to obtain a posture maintaining $\mathrm{HBM}$ and to simulate reflexive muscle responses. Human response to low level impact forces can be captured with different sets of controller parameters for a relaxed and a prepared state. Controller parameters derived using continuous perturbation experiments and linear estimation capture the response to low level impact forces using a non-linear musculoskeletal model. When implementing feedback control of muscles in an FE environment, it is important to ensure biofidelic sliding contacts with well defined motion. Moreover, the nodal masses of line muscle elements must be large enough to avoid small vibrations that can cause numerical problems with Hill-type muscle models.

The methodology developed can be applied to a full body FE HBM allowing simulation of interaction with pre-crash restraint systems, the response to pre-crash systems affecting the vehicle dynamics as well as other novel pre-crash and in-crash protective systems.

\section{Acknowledgements}

This research was funded by SAFER, the Vehicle and Traffic Safety Centre at Chalmers, as part of the project B8: Development of Active HBM in Frontal Impact Situations.

The authors would like to thank Dr. Erwin de Vlugt, Debbie Smans, Koen van de Poll, and Nienke van Hameren, at Delft Technical University, for their assistance with the volunteer experiments; Prof. Jac Wismans and Dr. Johan Davidsson, at Chalmers University of Technology, for their ideas and support; Dr. Thomas Borrvall, at Engineering Research Nordic AB, for the valuable help with the user control subroutine in the LS-DYNA ${ }^{\circledR}$ object version.

\section{References}

An KN, Hui FC, Morrey BF, Linscheid RL, Chao EY. 1981. Muscles across the Elbow Joint: A Biomechanical Analysis. J. Biomech. 14(10):659-669.

Aparicio F. 2005. EEVC WG19 Activities on Primary and Secondary Safety Interaction. Paper presented at: 19th International Conference on the Enhanced Safety of Vehicles; June 6-9; Washington (DC).

Barin K. 1989. Evaluation of a Generalized Model of Human Postural Dynamics and Control in the Sagittal Plane. Biol. Cybern. 61:37-50.

Behr M, Arnoux PJ, Serre T, Thollon L, Brunet C. 2006. Tonic Finite Element Model of the Lower Limb. J. Biomech. Eng. 128:223-228.

Brolin K, Halldin P, Leijonhufuvd I. 2005. The Effect of Muscle Activation on Neck Response. Traffic Inj. Prev. 6:67-76.

Brolin K, Hedenstierna S, Halldin P, Bass C, Alem N. 2008. The importance of muscle tension on the outcome of impacts with a major vertical component. Int. J. Crashworthiness. 13(5):487-498.

Brouwn GG. 2000. Postural control of the human arm. [PhD thesis]. [Delft, Netherlands]: Delft Technical University.

Buchanan TS, Delp SL, Solbeck JA. 1998. Muscular resistance to varus and valgus loads at the elbow. J Biomech Eng. 120:634-639. 
Budziszewski P, van Nunen E, Mordaka JK, Kędzior K. 2008. Active Controlled Muscles in Numerical Model of Human Arm for Movement in Two Degrees of Freedom. Paper presented at: International Conference on the Biomechanics of Impact; Sept. 17-19; Bern, Switzerland.

Cappon H, Mordaka J, van Rooij L, Adamec J, Praxl N, Muggenthaler H. 2007. A Computational Human Model with Stabilizing Spine: A Step Towards Active Safety, SAE Technical Paper no. 2007-01-1171, SAE International. Warrendale, PA, USA.

Chancey VC, Nightingale RW, Van Ee CA, Knaub KE, Myers BS. 2003. Improved estimation of human neck tensile tolerance: Reducing the range of reporter tolerance using anthropometrically correct muscles and optimized physiologic initial conditions. Stapp Car Crash J. 47:135-153.

de Jager MKJ. 1996. Mathematical Head-Neck Models for Acceleration Impacts. [PhD Thesis]. [Eindhoven, Netherlands]: Eindhoven University of Technology.

de Vlugt E, Schouten AC, van der Helm FCT, Teerhuis PC, Brouwn GG. 2003. A forcecontrolled haptic device for movement control analysis of the human arm. J. Neurosci. Methods 129:151-168.

de Vlugt E, Schouten AC, van der Helm FCT. 2006. Quantification of intrinsic and reflexive properties during multijoint arm posture. J. Neurosci. Methods 155:328-349.

Engin AE, Chen SM. 1987. Kinematic and Passive Resistive Properties of Human Elbow Complex. J Biomech. Eng. 109:318-323

European Commission. 2001. White paper - European transport policy for 2010: Time to decide. Brussels: European Commission - Mobility and Transport.

ETSC. Countdown to 2010 - only two more years to act! [Internet]. 2008. European Transport Safety Council; [cited 2010 May 24]: Available from: http://www.etsc.eu/documents/PIN_Conference_GJ_EU_falling_short_of_the_target.pdf

Fraga F, van Rooj L, Symeonidis I, Peldschus S, Happee R, Wismans J. 2009. Development and preliminary validation of a motorcycle rider model with focus on head and neck biofidelity, recurring to line element muscle models and feedback control. Paper presented at: 21st International Technical Conference on the Enhanced Safety of Vehicles; June 15-18; Stuttgart, Germany.

Gerdes VGJ, Happee R. 1994. The use of an internal representation in fast goal-directed movements: a modeling approach. Biol. Cybern. 70:513-524.

Hallquist J. 2006. LS-DYNA Theory manual. Livermore, CA, USA: Livermore Software Technology Corporation.

Hayes KC, Hatze, H. 1977. Passive visco-elastic properties of the structures spanning the human elbow joint. Europ. J. Appl. Physiol. 37:265-274.

Hedenstierna S, Halldin P. 2008. How Does a Three-Dimensional Continuum Muscle Model Affect the Kinematics and Muscle Strains of a Finite Element Neck Model Compared to a Discrete Muscle Model in Rear-End, Frontal, and Lateral Impacts. Spine. 33(8):E236E245.

Hedenstierna S, Halldin P, Brolin K. 2008. Evaluation of a combination of continuum and truss finite elements in a model of passive and active muscle tissue. Comput. Methods Biomech. Biomed. Engin. 11:627-639

Hill AV. 1970. The first and last experiments in muscle mechanics. Cambridge: University Press.

Holzbaur KRS, Murray WM, Delp, SL. 2005. A model of the upper extremity for simulating musculoskeletal surgery and analyzing neuromuscular control. Ann. Bio. Eng. 33(6):829840.

Hortobágyi T, Katch FI. 1990. Eccentric and concentric torque-velocity relationships during arm flexion and extension. Eur. J. Appl. Physiol. 60:395-401. 
Howell JN, Chleboun G, Conatser R. 1993. Muscle stiffness, strength loss, swelling and soreness following exercise-induced injury in humans. J. Physiol. 464:183-196.

Kou AD. 2005. An optimal state estimation model of sensory integration in human postural balance. J. Neural Eng. 2:S235-S249.

Marieb E. 1998. Human anatomy and physiology. 4th ed. Menlo Park: Benjamin/Cummings Science Publishing.

Murray WM, Buchanan T, Delp SL. 2000. The isometric functional capacity of muscles that cross the elbow. J. Biomech. 33:943-952.

Standring S. 2005. Gray's Anatomy - The anatomical basis of clinical practice. London, Elsevier Churchill Livingstone: Section 5, Pectoral girdle and upper limb; p. 799-942.

Toyota Motor Corporation, Toyota Central Labs Inc. 2008. Users' Guide of Computational Human Model THUMS ${ }^{\circledR}$ - AM50 Occupant Model: Version 3.0-080225.

van der Horst M. 2002. Human Head Neck Response in Frontal, Lateral and Rear End Impact Loading - Modeling and Validation. [PhD Thesis]. [Eindhoven, Netherlands]: Eindhoven University of Technology.

Veeger HEJ, Yu B, An K-N, Rozendal RH. 1997. Parameters for modeling the upper extremity. J. Biomech. 30(6):647-652.

Wiegner AW, Watts RL. 1986. Elastic properties of muscles measured at the elbow in man: I. normal controls. J. Neurol. Neurosurg. Psychiatry 49:1171-1176.

Wilkie DR. 1950. The relation between force and velocity in human muscle. J. Physiol. 110:249-280.

Winters JM, Stark L. 1985. Analysis of fundamental human movement patterns through the use of in-depth antagonistic muscle models. IEEET. Bio-Med. Eng. 32(10):826-839.

Winters JM, Stark L. 1987. Muscle models: What is gained and what is lost by varying muscle model complexity. Biol. Cybern. 55:403-420.

Winters JM, Stark L. 1988. Estimated mechanical properties of synergistic muscles involved in movements of a variety of human joints. J. Biomech. 21(12):1027-1041.

Wittek A, Kajzer J. 1997. Modeling the muscle influence on the kinematics of the head-neck complex in impacts. Mem. School Eng. Nagoya Univ. 49:155-205.

Wittek A. 2000. Mathematical Modeling of the Muscle Effects on the Human Body Responses under Transient Loads - Example of Head-Neck Complex. [PhD thesis]. [Gothenburg, Sweden]: Chalmers University of Technology.

Yamada H. 1970. Strength of biological materials. Baltimore (MD): Williams \& Wilkins.

Zajac FE. 1989. Muscle and tendon: Properties, models, scaling and application to biomechanics and motor control. Crit. Rev. Biomed. Eng. 17(4):359-411. 